then ro cc. of special diluted sulfuric acid (see above) are poured in. Ten minutes after this, the solution to be tested for arsenic is poured in. The presence of arsenic is determined by the coloring of the end of the strip nearest the bulb. The quantity of arsenic is determined by the depth to which the yellowish orange color attains. The method is sensitive to less than $0.001 \mathrm{mg}$. of arsenic.

All the glass and porcelain apparatus used must be tested for arsenic, and only such taken as proves to be free from it. The sulfuric acid is usually found to be free from arsenic. The greatest difficulty was encountered with the zinc, but the brand called "Bertha Spelter," from the New Jersey Zinc Com-

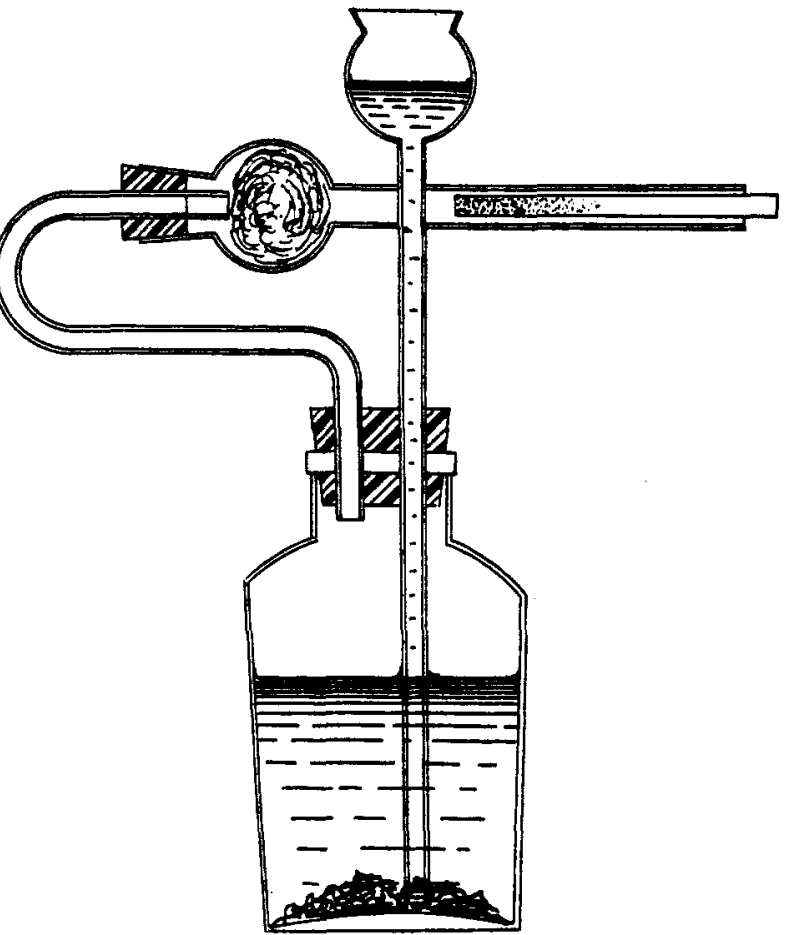

Fig. I. pany of New York, recommended by Sanger and Black, proved to be arsenic-free. The zinc was delivered to us in large pieces. These were melted in French clay crucibles and the molten mass poured into water, where it solidified in small pieces suitable for the experiments.

NEW YORK, N. Y.

\title{
PARTITION OF THE NITROGEN OF PLANT, YEAST, AND MEAT EXTRACTS.
}

By F. C. Coor. ${ }^{1}$

Received April 22, 1914.

Introduction.

An investigation of the nitrogenous and other constituents of meat extracts, bouillon cubes, and plant extracts was recently reported by Micko. ${ }^{2}$ In previous papers he ${ }^{3}$ discussed the purine bases of meat and

1 Physiological Chemist, Animal Physiological Chemistry Laboratory.

${ }^{2}$ Z. Nahr. Genussm., 26, 32 I (1913).

${ }^{3}$ Ibid., 5, I93 (1902); 6, 78x (1903). 
yeast extracts and stated that xanthine and hypoxanthine predominate in meat extracts, while adenine and guanine predominate in yeast extracts. The writer ${ }^{1}$ has published analyses and tests for distinguishing yeast extracts from meat extracts and has recommended the creatinine test as the most satisfactory. In a recent article he ${ }^{2}$ stated that meat extracts give higher total nitrogen results than plant extracts and suggested the value of the creatinine and phosphoric acid figures in determining the relative amount of meat extract present in bouillon cubes.

This study was undertaken in order to find some means of identifying the three classes of extracts, by determining the nitrogen constituents present, and to obtain information in regard to the nitrogenous composition of these extracts.

\section{Experimental.}

Description of Extracts.-Five samples of meat extract, one of yeast extract, and seven of plant extract, all of them commercial samples of unknown history, were examined. All had a pasty consistency and similar odor and taste. The meat extracts were semi-solid extracts, which are usually prepared by evaporating in vacuum pans the liquor obtained in the packing houses during the cooking of beef preparatory to canning. The yeast extract was prepared from exhausted beer yeast. The yeast, after being washed, yielded on hydrolysis a liquor which was subjected to the same general treatment as the liquor from the beef. The plant or vegetable extracts are more completely hydrolyzed products than either meat or yeast extracts. Such extracts are prepared from soy beans and concentrated extracts of vegetables and herbs, as leek, celery, parsnip and onion with the addition of sodium chloride after concentration in vacuum.

Description of Methods. - The total nitrogen ${ }^{3}$ was determined by the Kjeldahl-Gunning method. ${ }^{4}$ The samples were digested for four hours, as better results for total nitrogen are obtained when the digestion is carried on for four hours than for shorter periods.

Ammonia was determined by the Folin and Macallum ${ }^{5}$ method as outlined for urine. The precipitation with acid-alcohol has not been compared directly with other precipitation methods. This method has been used by Rippetoe to distinguish plant from meat extracts and was suggested by him to the writer. He outlines the procedure as follows:

"Transfer to cc. of an aqueous solution of the extract (Io cc. equal I g.) to a 200 cc. glass stoppered measuring cylinder, add $1.2 \mathrm{cc}$. of a $12 \%$ hydrochloric acid solution, mix and add absolute alcohol to $200 \mathrm{cc}$. mark, mix thoroughly and set aside for several

1 U. S. Dept. Agr. Bureau of Chemistry, Bull. 114 and Cir. 62.

2 J. Ind. Eng. Chem., 5, No. 12 (1913).

${ }^{3}$ The nitrogen determinations were made by the Nitrogen Laboratory of this Bureau.

4 U. S. Dept. Agr. Bureau of Chemistry, Bull. 107, Rev.

5 J. Biol. Chem., II, 523 (1912). 
hours at $20^{\circ}$ to $25^{\circ}$. If necessary, make up to mark, filter, and transfer $100 \mathrm{cc}$. to a Kjeldahl flask, evaporate alcohol on water bath and determine nitrogen in residue."

The tannin salt precipitation ${ }^{1}$ was carried out, using tannic acid of the highest purity obtainable, as required by this method. The writer in applying this reagent has always used a pure tannic acid which is stated to have been prepared from Chinese gall nuts.

Solutions of all the extracts were treated according to the formol titration method of Sörensen ${ }^{2}$ and the Van Slyke ${ }^{3}$ method for amino nitrogen. The dark color of the extracts interfered with the end points of the Sörensen method, and the results obtained were not satisfactory. The ammonia was determined in a separate sample and the results in the table are corrected for ammonia. The Van Slyke method was successfully applied to water solutions of the extracts.

Tabulation of Results.-Partition of the Nitrogen of Plant, Yeast and MEAT EXTRACTS.
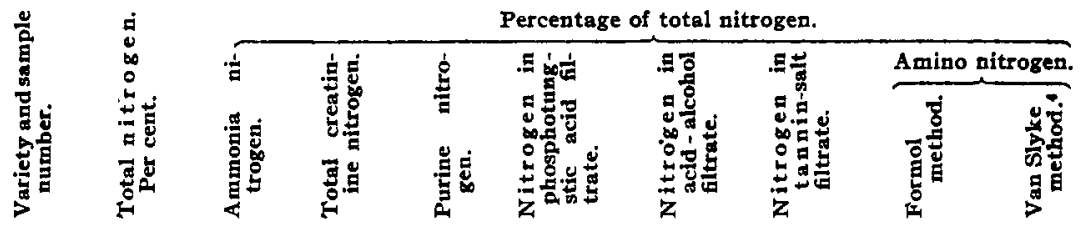

Meat

extracts:

\begin{tabular}{|c|c|c|c|c|c|c|c|c|c|}
\hline I & 9.56 & 2.62 & 22.49 & $3 \cdot 35$ & 7.64 & 78.04 & $54.9 \mathrm{I}$ & 10.94 & 18.50 \\
\hline 2 & 9.65 & 2.49 & 22.59 & $3 \cdot 52$ & 6.84 & 78.45 & 55.85 & 10.94 & 18.23 \\
\hline 3 & 7.68 & I. 56 & 32.42 & 2.86 & 71.35 & 100.00 & 73.04 & 10.63 & 15.63 \\
\hline 4 & 9.65 & . & 29.01 & 4.92 & $49 \cdot 74$ & 76.73 & 59.37 & $10.27^{5}$ & $15 \cdot 54$ \\
\hline 5 & 7.49 & . & 27.50 & 0.13 & $\ldots$ & 89.19 & 64.21 & 9.53 & 17.89 \\
\hline \multicolumn{10}{|c|}{$\begin{array}{l}\text { Yeast } \\
\text { extract: }\end{array}$} \\
\hline 6 & $5 \cdot 35$ & 2.43 & 0 & 11.22 & 49.96 & 72.15 & 56.07 & I7.64 & $32.7 \mathrm{I}$ \\
\hline \multicolumn{10}{|c|}{$\begin{array}{l}\text { Plant } \\
\text { extracts: }\end{array}$} \\
\hline 7 & 5.23 & $7 \cdot 46$ & 0 & 0.42 & 85.85 & 100.00 & 94.46 & 36.71 & $65 \cdot 77$ \\
\hline 8 & 6.34 & 12.78 & 0 & 0.44 & 84.08 & 99.69 & 89.95 & 36.43 & $57 \cdot 41$ \\
\hline 9 & 6.33 & $\ldots$ & 0 & 0.25 & . & $100, \infty$ & 83.41 & 30.64 & $45 \cdot 18$ \\
\hline 10 & 6.27 & I I. 32 & o & 0.44 & 83.25 & 98.56 & 92.66 & 35.88 & $67 \cdot 78$ \\
\hline I I & 6.47 & 6.03 & o & $\ldots$ & 63.68 & 100.00 & 84.54 & 30.75 & 44.20 \\
\hline 12 & 6.08 & 12.98 & 0 & 0.46 & 84.04 & 99.67 & 92.76 & 35.85 & 6 I.18 \\
\hline I 3 & 6.63 & IO. 56 & 0 & 0.23 & 86.88 & 99.25 & $9 \mathrm{I} .40$ & 34.08 & $57 \cdot 31$ \\
\hline
\end{tabular}

Total creatinine was determined by the Benedict-Myers ${ }^{6}$ autoclave

1 J. Am. Chem. Soc., 12, 1485 (1906).

2 Biochem. Zeit., 7, 45 (1908).

8 J. Biol. Chem., 9, 185 (I9II).

$415 \%$ of ammonia nitrogen included.

${ }^{5}$ No correction for ammonia; no determination.

6 Am. J. Physiol., r8, 397 (1907). 
method, and purine nitrogen according to Schittenhelm, ${ }^{1}$ as applied to meat extracts by the writer. ${ }^{2}$

\section{Discussion of Results.}

As seen in the table, the meat extracts gave higher total nitrogen results than the plant or yeast extracts. Nevertheless, more ammonia was obtained from the plant than from the meat extracts. Micko reports $4.22 \%$ of total nitrogen, as ammonia nitrogen, in a sample of meat extract and states that the ammonia nitrogen should never exceed $6 \%$ of the total nitrogen of a meat extract. His results were obtained by distilling with magnesium oxide and are considerably higher than the ammonia results given in the table, which were obtained by the Folin method. The magnesium oxide method is recognized as yielding more than the ammonia nitrogen. ${ }^{3}$ The results for the plant extracts vary from 6.03 to $12.98 \%$ of the total nitrogen and are so much higher than the meat extract figures that the ammonia determination becomes of value in distinguishing a plant from a meat extract.

The plant and yeast extracts gave no biuret reaction, and are therefore more completely hydrolyzed products than the meat extracts, which gave this test. Meat extract Samples 3 and 5 were exhausted before this test was made.

Only the total creatinine present in the meat extracts was determined. Some creatine, as well as creatinine, is present, but, both having a common origin, namely, the creatine of the muscle, there is no object in determining the relative amounts of these two substances. No creatine or creatinine was found in the plant and yeast extracts. Their absence makes this determination of the greatest value in distinguishing a yeast or plant extract from a meat extract. The total creatinine nitrogen comprises from $22.49 \%$ to $32.42 \%$ of the total nitrogen of the meat extracts reported in the table. Micko, in referring to the creatinine content of meat extracts, stated that $20 \%$, or more, of the nitrogen of a meat extract is present as creatinine nitrogen.

The purine nitrogen results for the plant extracts were exceedingly low, the highest yielding but $0.46 \%$ of the total nitrogen as purine nitrogen. The yeast extract contained I I.22\% of its nitrogen as purine nitrogen, and the meat extracts, with the exception of extract No. 5, gave from 2.86 to $4.92 \%$ of their nitrogen in this form. Micko reports $7.3 \%$ of the nitrogen of a meat extract as purine nitrogen and states that the purine nitrogen of meat extracts should comprise from 6 to $8 \%$ of the total nitrogen. These figures are higher than the results reported on the table, which were obtained by the Schittenhelm method. The method employed by Micko

1 Z. Physiol. Chem., 39, 199 (1903).

${ }^{2}$ U. S. Dept. Agr., Bur. of Chem., Bull. rr4.

${ }^{3}$ Ibid., 132, p. 20. 
was the method of the "Codex Alimentarius Austriacus." The results for purine nitrogen are interesting, not only in showing analytical differences in the plant and meat extracts, but also for the reason that no determinations for purine nitrogen in plant extracts have been reported in the literature ${ }^{1}$ so far as the writer knows.

Comparison of the Precipitation Methods. -The plant extracts gave a much larger percentage of nitrogen in the phosphotungstic acid filtrate than the yeast or meat extracts. All of the nitrogen of the plant extracts was present in the hydrochloric acid-alcohol filtrate. This was true of meat extract No. 3 in the table. Similarly the tannin-salt reagent, when applied to plant extracts, showed most of the nitrogen in the filtrate. The yeast extract gave a cloudy filtrate from the acid-alcohol and tanninsalt precipitations; all the other extracts gave clear filtrates in these cases.

Comparison of Formol and Van Slyke Methods.-The formol method gave lower figures for amino nitrogen than the gasometric method of Van Slyke. As the formol method should include both the amino nitrogen and ammonia nitrogen, we would expect to obtain higher results than with the Van Slyke method, which includes the simple aliphatic amino nitrogen and $15 \%$ of the ammonia nitrogen. The formol method is based on the idea that for each carboxyl group there is a corresponding amino group. The amino groups combine with the formaldehyde and the carboxyl groups are free to be titrated with standard alkali. That this does not hold true in these extracts is apparent from the results obtained. The results by the formol and Van Slyke methods, however, show the same general tendencies as the precipitation methods, that is, where the precipitating reagents gave a low percentage of nitrogen in the filtrate (amino nitrogen) low amino nitrogen figures were obtained by these two methods. From the point of view of accuracy the Van Slyke method is undoubtedly superior to the formol method, which apparently gives results which are far too low when applied to extracts, as has been done here; and that, in spite of the tendency to overrun the end point on account of the dark colored solution of the extracts.

\section{Summary.}

There is great variation in the precipitating power of the different reagents compared. Photosphungstic acid precipitated the highest, tannin-salt the next highest, and acid-alcohol the lowest percentage of the nitrogen of the extracts examined.

The formol titration method of Sörensen gave lower results for the amino nitrogen in meat, plant, and yeast extracts than the Van Slyke method.

All of these methods showed that a larger percentage of the nitrogen

${ }^{1}$ Since the above was written Micko's paper (Loc. cit.) appeared, which contains four purine nitrogen results for plant extracts. 
was present in a more completely hydrolyzed state, in the plant than in the yeast or meat extracts.

No creatine or creatinine and very little purine nitrogen was found in the plant extracts. The yeast extract showed high purine nitrogen and no creatine or creatinine. Plant and yeast extracts gave no biuret reaction but the meat extracts examined gave this reaction.

All of the nitrogen of the plant extracts was found in the filtrate after applying acid-alcohol, and consists chiefly of mono-amino acids and ammonia. About $25 \%$ of the nitrogen of the meat and yeast extracts is precipitated by acid-alcohol. The plant extracts yield a much larger percentage of nitrogen as ammonia nitrogen than the meat or yeast extracts.

In differentiating these three classes of extracts, the creatinine, ammonia, purine nitrogen and acid-alcohol determinations are of value to the food analyst.

Bureau OF Chemistry,

DEPARTMENT OF AGRICULTURA, Waskington, D. C.

[Contribution No. 37 from the Laboratory of Biological Chemistry of the Station For EXPERIMENTAL EVOLUTION, THE CARNEGIE INSTITUTION OF WASHINGTON.]

\title{
STUDIES ON THE CHEMISTRY OF EMBRYONIC GROWTH. II. COMPARATIVE ANALYSES OF THE EGGS AND OF THE NEWIY-HATCHED LARVAE OF THE GIANT SALA- MANDER, CRYPTOBRANCHUS ALLEGHENIENSIS.
}

\author{
By Ross Arken Gortser. \\ Received April 30, 1914. \\ Introduction.
}

The Problem.-The purpose of this investigation is identical with that of the first paper in this series (Gortner, I9I3), i. e., to determine whether the "chemical compounds which are present in the egg enter the growing tissues in the same form in which they are laid down in the egg, or whether synthetic changes are also taking place so that the material which is present in the egg is used, not in its original form but in a modified condition."

The distribution of the nitrogenous compounds in the various stages of development offers the easiest method of attack. In the preceding paper I presented a study of the nitrogen distribution in fresh eggs of the brook trout (Savelinus fontinalis L.), and in embryos and young fry at different stages in their development. The present paper is devoted to a somewhat similar study of the eggs and of the newly-hatched larvae of the salamander, Cryptobranchus Allegheniensis, Daudin.

The Material.-The eggs of Cryptobranchus have proved to be a excellent material for chemical studies. In most amphibian eggs the tough 